86 Bauer: Apparat zur Bestimmung von Kohlensäure etc.

\title{
Apparat zur Bestimmung von Kohlensäure (Carbonaten) und allen ähnlichen Gasen; \\ von
}

\author{
Prof. Dr. R. Bauer.
}

Im Jahrgang 1884, Bd. 29, S. 489 dieser Zeitschrift habe ich einen für obige $Z_{w}$ ecke bestimmten Apparat angegeben, welcher sich seitdem nicht nur in vielen chemischen Laboratorien, sondern auch im Fabrikgebrauch selbst (also auch in des Hand der Nichtchemikers) durch die grosse. Einfachheit seiner Construction und die Zuverlässigkeit der damit erhaltenen Resultate sehr schnell beliebt gemacht hat. Neuestens ist derselbe nun dadurch noch wesentlich von mir verbessert und stabiler gemacht worden, dass die etwas zerbrechliche Trichterröhre und der ebenfalls zu Reparaturen Anlass gebende Dreiweghahn jetzt ganz in Wegfall gekommen sind. Der Ersatz der Trichterröhre ist obne Weiteres aus der S. 87 beigegeben Skizze zu verstehen, derjenige des Dreiweghahns dadurch erreicht, dass an dem oberen freien Ende des Kugelentwicklungsrohres ein kleines Loch angebracht ist, über welches sich ein Kautschukrohrabschnitt leicht hin und her schieben, d. h. der Apparat sich beliebig schliessen und öffnen lässt. Die Function des Dreiweghahns ist in einer Weise hergestellt, wie sie wohl einfacher, sicherer und gefahrloser nicht weiter möglich sein wird, und auch keiner näheren Beschreibung bedarf. Der Kautschukabschnitt wird zweckmässig von Zeit zu Zeit mit einem Tropfen fetten, nicht trocknenden Oels auf der inneren Seite versehen. Was den sonstigen Gebrauch des Apparates betrifft, so verweise ich auf die frühere Beschreibung und füge noch bei, dass genaue Wägung des Untersuchungsmaterial durchaus nothwendig und es ebenso unerlässlich ist, gerade nur so viel Zersetzungsäure (conc. $\mathrm{HCl}$ und $\mathrm{H}_{2} \mathrm{O}$ zu gleichen Theilen) 
Bauer: Apparatzur Bestimmung von Kohlensäure etc. 87 $z u$ nehmen, als eben zur Austreibung des Gases erfordert wird. Ich gebe dem Apparat die (zunächst auf Kalkcarbonat) bezügliche Tabelle bei, aus der, wenn man das Untersuchungsmaterial im vorgeschriebenen Gewichte zersetzt, direct die erhaltenen Procente an reinem Carbonat ersichtlich sind. Will man das Untersuchungsmaterial (innerhalb der dem Apparat passenden Grenzen) beliebig abwägen, so sind in den gleichen Zablen, durch Kommata charakterisirt, die je einem $\mathrm{Ccm} . \mathrm{CO}_{2}$ - Gas entsprechenden Mengen Carbonat ausgedrückt.

Begreiflicherweise lässt sich der Apparat zu allen Gasbestimmungen analoger Natur, wie auch zur Acidjmetrie verwenden, indem man im letzteren Falle eben die Untersuchungssubstanz in das Entwicklungsgefäss, die Soda etc. aber in das Kugelrohr giebt. - Verdünnungen sind wegen der sonst fühlbar werdenden Absorption möglichst zu umgehen oder vorher wegzuschaffen.

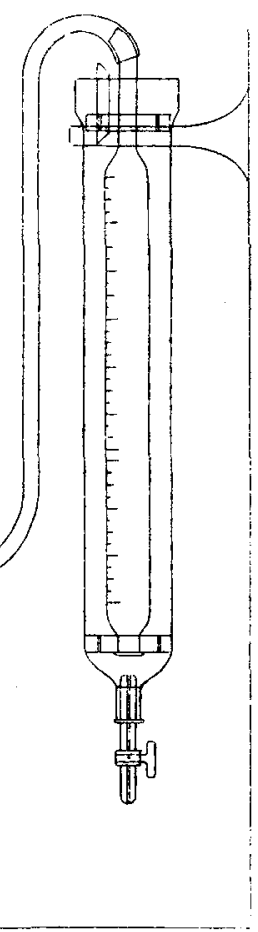

Der Apparat, welcher zum Patent angemeldet ist, $k a n n$ in verschiedenen Grössen von mir bezogen werden und wird in dieser neuen Form sich gewiss viele Freunde erwerben.

Stuttgart, November 1886 . 